\title{
A modular approach to two-photon absorbing organic nanodots: brilliant dendrimers as an alternative to semiconductor quantum dots? $\uparrow$
}

\author{
Olivier Mongin, ${ }^{a}$ Thatavarathy Rama Krishna,${ }^{b}$ Martinus H. V. Werts, ${ }^{a}$ Anne-Marie Caminade, ${ }^{b}$ \\ Jean-Pierre Majoral, ${ }^{* b}$ and Mireille Blanchard-Desce ${ }^{* a}$
}

\author{
Receipt/Acceptance Data [DO NOT ALTER/DELETE THIS TEXT] \\ Publication data [DO NOT ALTER/DELETE THIS TEXT] \\ DOI: 10.1039/b000000x [DO NOT ALTER/DELETE THIS TEXT]
}

\begin{abstract}
Nanoscopic fluorescent dendrimers having up to 96 two-photon chromophores and showing giant two-photon absorption crosssections (up to $56000 \mathrm{GM}$ ) were designed as a complementary "organic" alternative to quantum dots.
\end{abstract}

For more than a decade, two-photon absorption (TPA) has attracted increasing attention in relation with various applications, such as 3-D microfabrication, ${ }^{1}$ optical data storage, ${ }^{2}$ photodynamic therapy, ${ }^{3}$ and optical power limiting. ${ }^{4}$ Two-photon-excited fluorescence (TPEF) has been found to be of particular interest for the biological community: two-photon laser scanning fluorescence microscopy offers the advantages of imaging deeper in living tissues (down to $500 \mu \mathrm{m}$ ), with reduced photodamage and background fluorescence and with 3-D spatial resolution. ${ }^{5}$ In addition to biological imaging, TPEF can also be of interest for 3-D imaging in materials. These applications call for the design of new fluorophores whose TPA cross-sections are optimised in the spectral range of interest: $700-1200 \mathrm{~nm}$ corresponding to the combination of reduced scattering and minimal absorption in (bio)organic materials. Aside from efforts in molecular engineering of optimised chromophores with very large TPEF cross-sections, ${ }^{6}$ semiconductor nanocrystals (quantum dots: QD) have shown to provide a particularly effective approach to fluorescent labels with extremely large TPEF cross-sections (up to $47000 \mathrm{GM}$ ) for imaging in living tissues. ${ }^{7}$

Here, we show that organic "nanodots" built from the grafting of a discrete and large number of optimised two-photon (TP) chromophores on the periphery of dendrimers can provide a complementary approach towards nanoscale fluorescent systems with very large TPEF cross-sections. Apart from the complementarity in terms of advantages and drawbacks of organic nanodots and quantum dots (which make both tools of interest depending on the criteria), this offers a modular route for (i) molecular control of photophysical properties, (ii) modulation of solubility in various environments (via addition of external solubilising groups) and (iii) further covalent functionalisation for additional functionality.

Recent work has shown that conjugated dendrimers based upon the assembly of TP chromophores in dendrimeric architectures ${ }^{8}$ exhibit very large TPA cross-sections (up to 11000 GM). Pioneering work by Prasad and Fréchet shows that covalent assembling of TP chromophores within a more flexible dendrimeric

\footnotetext{
* mireille.blanchard-desce@univ-rennes1.fr (Mireille Blanchard-Desce) majoral@1cc-toulouse.fr (Jean-Pierre Majoral)

$\dagger$ Electronic supplementary information (ESI) available: synthesis and
} characterisation data. assembly leads to high TPA cross-sections (up to 2600 GM for 8 chromophores $)^{9}$ Such dendritic systems can be derivatised by using an acceptor core leading to interesting systems based on Förster resonance energy transfer for two-photon induced photoluminescence ${ }^{10}$ or even singlet oxygen formation. ${ }^{11}$

Aiming at a different purpose (i.e. achieving giant TPA crosssections in combination with high fluorescence quantum yields), we have designed dendritic systems bearing up to 96 strongly TPAactive fluorophores $^{12}$ (Fig. 1).

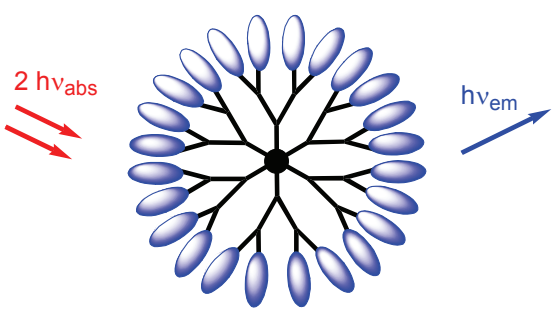

Fig. 1 Schematic representation of dendrimeric two-photon absorbing fluorescent organic "nanodots"

These systems were built by grafting of an exponentially increasing number of TP-active chromophore 1 on the periphery of phosphorus dendrimers of generation 1 to 4 decorated with terminal $\mathrm{P}(\mathrm{S}) \mathrm{Cl}_{2}$ groups. ${ }^{13}$ Chromophore 1 was prepared in a three-step sequence starting from commercially available aniline $\mathbf{2 a}$, involving iodination, Mitsunobu reaction with hydroquinone and Sonogashira coupling with alkyne 4 (Scheme 1). Nucleophilic substitutions involving $\mathrm{P}(\mathrm{S}) \mathrm{Cl}_{2}$ end groups ${ }^{14}$ and $\mathbf{1}$ take place easily leading to dendrimers $\mathbf{G 1 , ~ G 2 , ~ G 3 ~ a n d ~} \mathbf{G 4}$ bearing respectively 12, 24, 48 and 96 chromophores (Scheme 2).

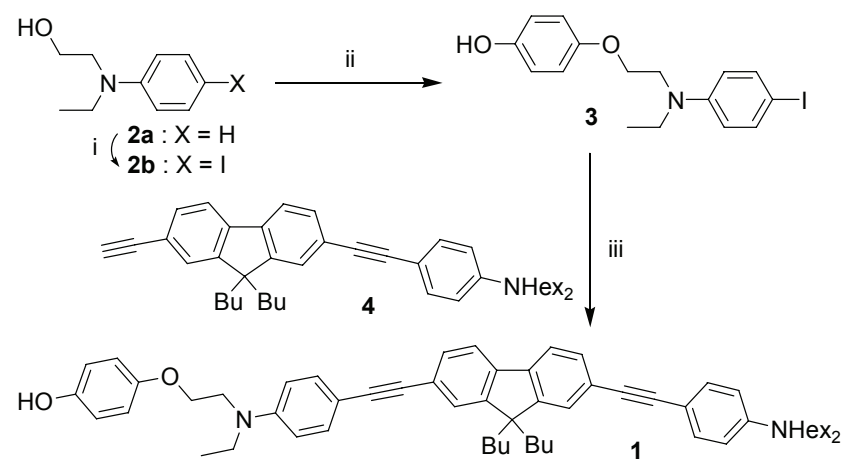

Scheme 1: i, $\mathrm{I}_{2}, \mathrm{NaHCO}_{3}, \mathrm{CH}_{2} \mathrm{Cl}_{2}(86 \%)$; ii, hydroquinone (3 equiv.), DEAD, $\mathrm{PPh}_{3}$, THF, rt, 16 h (51\%); iii, 3, $\mathrm{Pd}\left(\mathrm{PPh}_{3}\right)_{2} \mathrm{Cl}_{2}, \mathrm{CuI}$, toluene/ $\mathrm{Et}_{3} \mathrm{~N}$, $40{ }^{\circ} \mathrm{C}, 16 \mathrm{~h}(57 \%)$. 


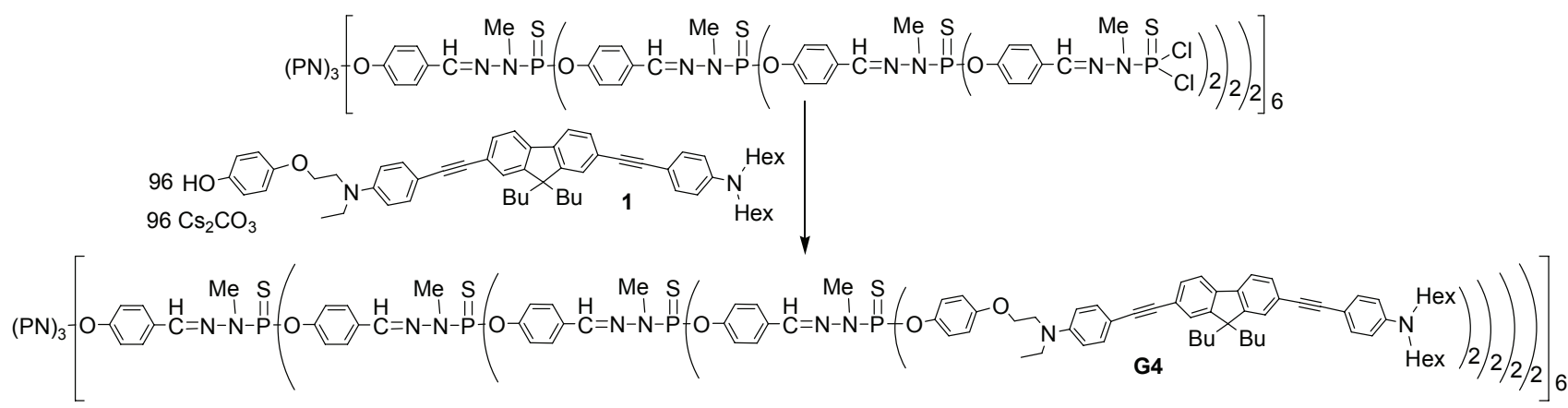

Scheme 2 Synthesis of the $4^{\text {th }}$ generation dendrimer bearing 96 fluorophore end groups

Dendrimers G1-G4 show strong one-photon absorption in the near UV with a nearly linear increase of the extinction coefficient with the number of chromophores (Table 1). This is a good indication of efficient functionalisation of the dendrimers.

Interestingly all chromophores maintain a reasonably high fluorescence quantum yield (Table 1). A broadening of the emission band is observed, as well as a clear loss of fine structure (in addition to change of relative vibronic intensities), with increasing the generation (Fig. 2), most probably in relation with inhomogeneous broadening and change in reorganization energy.

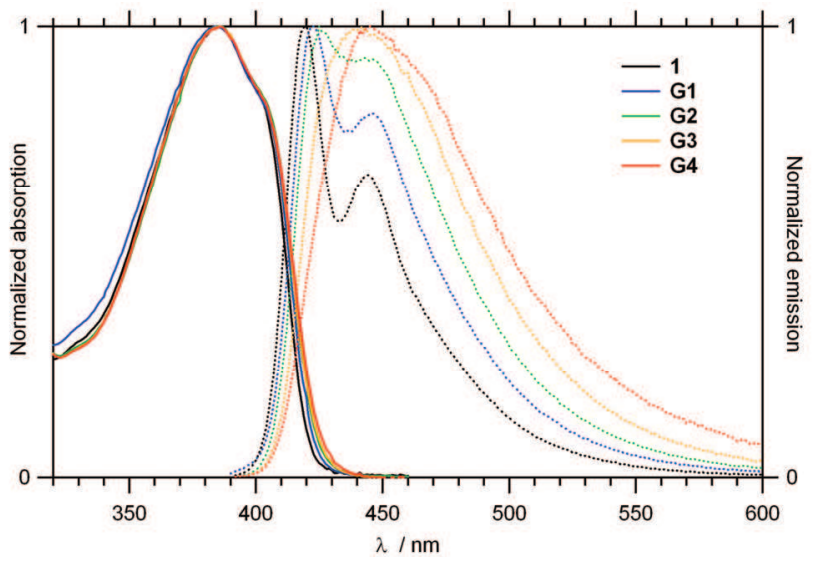

Fig. 2 Normalized absorption and emission spectra in toluene of dendrimers G1-G4 and model chromophore $\mathbf{1}$.

Also a decrease in fluorescence quantum yield is observed with increasing the generation. The reason for this decrease is as yet unclear, but might be related to interchromophoric interactions $\S$. Even tough, G4 maintains a fluorescence quantum yield of about $50 \%$, which shows that the implemented strategy is fruitful.

TPA measurements were conducted by investigating the TPEF of dendrimers G1-G4 in toluene $\mid$. TPEF measurements allows for direct measurement of the TPEF action cross-section $\sigma_{2} \Phi$, the relevant figure of merit for imaging applications. In addition this method has been recognized as more reliable than nonlinear transmission measurements. ${ }^{15}$

The quadratic dependence of the TPEF signal on the excitation intensity was checked for each data point, indicating that no photodegradation or saturation occurs. The TPA spectrum of monomeric chromophore $\mathbf{1}$ was also determined for comparison. As clearly seen from Fig. 3, a major increase in TPA cross-sections is observed in the whole spectral range of interest with increasing the generation. Indeed a quasi-linear increase with the number of chromophores is obtained leading to very large $\sigma_{2}$ values for the dendrimer nanodots. This linear increase with the number of chromophores suggests that the strategy could be extended to even higher generations (Fig. 3). The maximum value (55 $900 \mathrm{GM}$ at $705 \mathrm{~nm}$ ) obtained for $\mathbf{G 4}$ is comparable to the $\sigma_{2}$ value measured by Webb and co-workers ${ }^{7}$ for the best reported luminescent markers, semiconductor quantum dots. Organic "nanodot" G4 is about the same size (its diameter can be estimated to be about 8 $\mathrm{nm}^{16}$ ) as these QDs (6 $\mathrm{nm}$ diameter without the encapsulating polymers). In addition, though quantum dots have several advantages (such as robustness and photostability), the quantum dots made from cadmium selenide and zinc sulfide suffer from toxicity drawbacks which might be a problem for specific imaging applications - in marked contrast with the very low toxicity detected for phosphorus dendrimers. ${ }^{17}$ Also organic "nanodots" are more flexible in terms of covalent functionalisation and size control.

In conclusion, the present results demonstrate that organic "nanodots" represent a promising approach towards fluorescent markers with giant TPA cross-sections and provide luminescent systems complementary to semiconductor QD. In addition the modular route allows access towards a variety of organic nanodots with different fluorophores, allowing tuning of the photoluminescence properties.

Table 1 Photophysical data for model fluorophore 1 and dendrimers G1-G4 in toluene.

\begin{tabular}{ccccccccc} 
& $\begin{array}{c}\text { Number of } \\
\text { fluorophores }\end{array}$ & $\begin{array}{c}\lambda_{\mathrm{abs}} \\
(\mathrm{nm})\end{array}$ & $\begin{array}{c}\varepsilon \\
\left(\mathrm{M}^{-1} \cdot \mathrm{cm}^{-1}\right)\end{array}$ & $\begin{array}{c}\lambda_{\mathrm{em}} \\
(\mathrm{nm})\end{array}$ & $\Phi^{a}$ & $\begin{array}{c}\tau \\
(\mathrm{ns})^{b}\end{array}$ & $\begin{array}{c}\lambda_{\text {TPA }}(\max ) \\
(\mathrm{nm})\end{array}$ & $\begin{array}{c}\sigma_{2} \\
\text { at } \lambda_{\text {TPA }}(\max ) \\
(\mathrm{GM})^{c}\end{array}$ \\
\hline $\mathbf{1}$ & 1 & 386 & 84900 & 420,444 & 0.83 & 0.67 & 702 & 765 \\
$\mathbf{G 1}$ & 12 & 385 & 1004000 & 423,446 & 0.75 & 0.71 & 701 & 8880 \\
$\mathbf{G 2}$ & 24 & 386 & 2035000 & 426,445 & 0.71 & 0.69 & 701 & 17700 \\
$\mathbf{G 3}$ & 48 & 386 & 3785000 & 441 & 0.62 & 0.71 & 701 & 29800 \\
$\mathbf{G 4}$ & 96 & 386 & 7101000 & 445 & 0.48 & 0.66 & 705 & 55900
\end{tabular}

${ }^{a}$ Fluorescence quantum yield in toluene determined relative to fluorescein in $0.1 \mathrm{~N} \mathrm{NaOH} .{ }^{b}$ Experimental fluorescence lifetime measured by timecorrelated single photon counting. ${ }^{c} 1 \mathrm{GM}=10^{-50} \mathrm{~cm}^{4}$.s.photon ${ }^{-1}$. 


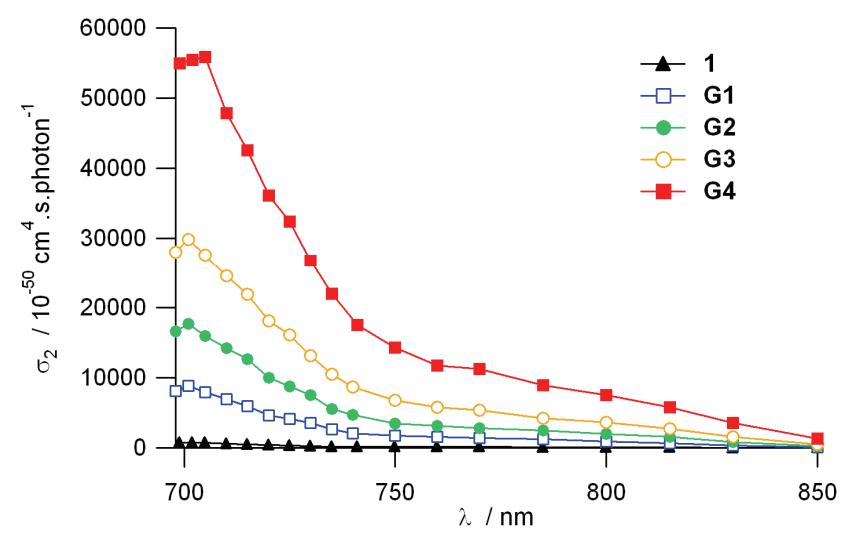

Fig. 3 TPA spectra of dendrimers G1-G4 and model chromophore 1 determined by femtosecond TPEF measurements in toluene.

In this communication, intended as a proof of principle, we have illustrated the strategy with quadrupolar type chromophores that are blue-emitters. Such route could also be applied to the grafting of quadrupoles that are green-emitters or even yellow emitters and show broader (and even higher) TPA. ${ }^{6 \mathrm{~b}}$ Further functionalisation may also be achieved. In particular adding supplementary layers and decorating the periphery with ammonium groups could yield hydrosoluble dendrimers. ${ }^{18}$

We gratefully acknowledge financial support from Rennes Métropole ("Allocation d'Installation Scientifique" awarded to MBD and MHVW). JPM thanks the Ministère de la Recherche (France) for the post-doctoral grant to TRK. We wish to thank Cédric Rouxel for his contribution to synthesis, and Adrien Gilot and Manuel Parent for their help in setting up the TPEF experiment.

Olivier Mongin, ${ }^{a}$ Thatavarathy Rama Krishna, ${ }^{b}$ Martinus H. V. Werts, ${ }^{a}$ Anne-Marie Caminade, ${ }^{b}$ Jean-Pierre Majoral, ${ }^{b b}$ and Mireille Blanchard-Desce ${ }^{* a}$

a Synthèse et Electrosynthèse Organiques (CNRS, UMR 6510), Université de Rennes 1, Campus Scientifique de Beaulieu, Bât. 10A, F-35042 Rennes Cedex, France. Tel-Fax: (+33) 2992862 77; E-mail: mireille.blanchard-desce@univ-rennes1.fr

${ }^{b}$ Laboratoire de Chimie de Coordination, CNRS, 205 route de Narbonne, F-31077 Toulouse Cedex 4, France. Fax: (+33) 5-61-55-30-03; E-mail: majoral@lcc-toulouse.fr

\section{Notes and references}

† TPA data derived from femtosecond measurements.

$\S$ Identification of the nature of the interaction (changes in the local field experienced by the chromophores, excitonic coupling, energy transfer...) will be the subject of future studies, but lies outside the scope of this communication.

I TPA measurements were conducted by investigating their TPEF in toluene using a Ti-sapphire laser delivering $150 \mathrm{fs}$ excitation pulses, according to the experimental protocol established by $\mathrm{Xu}$ and Webb. ${ }^{19}$ This experimental protocol allows avoiding contributions from excitedstate absorption that are known to result in largely overestimated TPA cross-sections. Fluorescein in $0.01 \mathrm{M} \mathrm{NaOH}$ was used as a reference, taking into account the necessary corrections for the refractive index of the solvents. ${ }^{20}$
1 (a) S. Kawata, H.-B. Sun, T. Tanaka, K. Takada, Nature 412 (2001) 697-698. (b) W. Zhou, S.M. Kuebler, K.L. Braun, T. Yu, J.K. Cammack, C.K. Ober, J.W. Perry, S.R. Marder, Science 296 (2002) 1106-1109.

2 (a) D.A. Parthenopoulos, P.M. Rentzepis, Science 245 (1989) 843845. (b) J.H. Strickler, W.W. Webb, Opt. Lett. 16 (1991) 1780-1782.

3 J. D. Bhawalkar, N. D. Kumar, C. F. Zhao and P. N. Prasad, J. Clin. Laser Med. Surg., 1997, 15, 201.

4 (a) G.S. He, G.C. Xu, P.N. Prasad, B.A. Reinhardt, J.C. Bhatt, A.G. Dillard, Opt. Lett. 20 (1995) 435-437. (b) J.E. Ehrlich, X.L. Wu, I.Y.S. Lee, Z.-Y. Hu, H. Röckel, S.R. Marder, J.W. Perry, Opt. Lett. 22 (1997) 1843-1845.

5 W. Denk, J. H. Strickler and W. W. Webb, Science, 1990, 248, 73.

6 (a) S.-J. Chung, K.-S. Kim, T.-C. Lin, G. S. He, J. Swiatkiewicz and P. N. Prasad, J. Phys. Chem. B, 1999, 103, 10741; (b) L. Ventelon, M. Blanchard-Desce, L. Moreaux and J. Mertz, Chem. Commun., 1999, 2055; (c) O.-K. Kim, K.-S. Lee, H. Y. Woo, K.-S. Kim, G. S. He, J. Swiatkiewicz and P. N. Prasad, Chem. Mater., 2000, 12, 284; (d) M. Rumi, J. E. Ehrlich, A. A. Heikal, J. W. Perry, S. Barlow, Z.Y. Hu, D. McCord-Maughon, T. C. Parker, H. Röckel, S. Thayumanavan, S. R. Marder, D. Beljonne and J.-L. Brédas, J. Am. Chem. Soc., 2000, 122, 9500; (e) L. Ventelon, S. Charier, L. Moreaux, J. Mertz and M. Blanchard-Desce, Angew. Chem., Int. Ed., 2001, 40, 2098; (f) B. R. Cho, K. H. Son, H. L. Sang, Y.-S. Song, Y.K. Lee, S.-J. Jeon, J. H. Choi, H. Lee and M. Cho, J. Am. Chem. Soc., 2001, 123, 10039; ( $g$ ) O. Mongin, L. Porrès, L. Moreaux, J. Mertz and M. Blanchard-Desce, Org. Lett., 2002, 4, 719; (h) W. J. Yang, D. Y. Kim, C. H. Kim, M.-Y. Jeong, S. K. Lee, S.-J. Jeon and B. R. Cho, Org. Lett., 2004, 6, 1389; (i) C. Le Droumaguet, O. Mongin, M. H. V. Werts and M. Blanchard-Desce, Chem. Commun., 2005, 2802.

7 D. R. Larson, W. R. Zipfel, R. M. Williams, S. W. Clark, M. P. Bruchez, F. W. Wise and W. W. Webb, Science, 2003, 300, 1434.

8 (a) M. Drobizhev, A. Karotki, A. Rebane and C. W. Spangler, Opt. Lett., 2001, 26, 1081; (b) M. Drobizhev, A. Karotki, Y. Dzenis, A. Rebane, Z. Suo and C. W. Spangler, J. Phys. Chem. B, 2003, 107, 7540; (c) O. Mongin, J. Brunel, L. Porrès and M. Blanchard-Desce, Tetrahedron Lett., 2003, 44, 2813.

9 A. Adronov, J. M. J. Fréchet, G. S. He, K.-S. Kim, S.-J. Chung, J. Swiatkiewicz and P. N. Prasad, Chem. Mater., 2000, 12, 2838.

10 D. W. Brousmiche, J. M. Serin, J. M. J. Fréchet, G. S. He, T.-C. Lin, S.-J. Chung, P. N. Prasad, R. Kannan and L.-S. Tan, J. Phys. Chem. $B, 2004, \mathbf{1 0 8}, 8592$.

11 W. R. Dichtel, J. M. Serin, C. Edder, J. M. J. Fréchet, M. Matuszewski, L.-S. Tan, T. Y. Ohulchanskyy and P. N. Prasad, J. Am. Chem. Soc., 2004, 126, 5380.

12 O. Mongin, M. Charlot, C. Katan, L. Porrès, M. Parent, T. Pons, J. Mertz and M. Blanchard-Desce, Proc. SPIE-Int. Soc. Opt. Eng., 2004, 5516, 9 .

13 (a) C. Galliot, C. Larré, A.-M. Caminade and J.-P. Majoral, Science, 1997, 277, 1981; (b) J.-P. Majoral and A.-M. Caminade, Chem. Rev., 1999, 99, 845; (c) J.-P. Majoral, A.-M. Caminade and V. Maraval, Chem. Commun., 2002, 2929; (d) A.-M. Caminade and J.-P. Majoral, Acc. Chem. Res., 2004, 37, 341.

14 N. Launay, A.-M. Caminade, R. Lahana and J.-P. Majoral, Angew. Chem., Int. Ed., 1994, 33, 1589.

15 D. A. Oulianov, I. V. Tomov, A. S. Dvornikov and P. M. Rentzepis, Opt. Commun., 2001, 191, 235.

16 M. Slany, M. Bardaji, M.-J. Casanove, A.-M. Caminade, J.-P. Majoral and B. Chaudret, J. Am. Chem. Soc., 1995, 117, 9764.

17 M. Maszewska, J. Leclaire, M. Cieslak, B. Nawrot, A. Okruszek, A.M. Caminade and J.-P. Majoral, Oligonucleotides, 2003, 13, 193.

18 A.-M. Caminade and J.-P. Majoral, Prog. Polym. Sci., 2005, 30, 491.

19 C. Xu and W. W. Webb, J. Opt. Soc. Am. B, 1996, 13, 481.

20 M. H. V. Werts, N. Nerambourg, D. Pélégry, Y. Le Grand and M. Blanchard-Desce, Photochem. Photobiol. Sci., 2005, 4, 531. 